\title{
Identifying human property measurements for user-centered design based on user scenarios
}

\author{
Heekyung Moon ${ }^{1}$, Sung H. Han ${ }^{1, *}$, Bora Kang ${ }^{1}$, Dongyeong Jung ${ }^{1}$ \\ ${ }^{1}$ Department of Industrial and Management Engineering, POSTECH, Pohang, Korea \\ *Shan@postech.edu
}

\begin{abstract}
User-centered design (UCD) gives extensive attention to human's physical, cognitive, and psychological characteristics at every stage of the product and service design process. Most of human property measurements currently available in UCD are limited to the physical body dimensions such as length or girth of a particular body part. This study aims to derive new concepts of human property measurements such as perceptional and cognitive characteristics from user scenarios. User scenarios were generated by combining factor levels, each belong to three factors such as user profile, user state, and environment. A total of 60 user scenarios were created and analyzed to derive relevant human property measurements, for example, sensory ability (visual/auditory/tactile), dynamic range of motion, and emotional/mental state, etc. The results demonstrated that various human property measurements could be efficiently derived from the user scenarios, without resorting to cost/time-consuming methods such as an observation and interview. The list of human property measurements derived in this study would be systematically measured and disseminated to be used for designing user-centered products and services in the further research.
\end{abstract}

Keywords: anthropometric data, body size, body dimension

\section{Introduction}

To design an ergonomic product or service, the human body dimensions are an inevitable requirement in the design process [1]. Designers thus try to make their products and services compatible with such body dimensions. The application area of human body dimensions is rapidly expanding as new types of products/services continue to emerge, including wearable devices and virtual environments. To enhance user performance and productivity, new types of human body dimensions for effective designs should be defined and measured.

Most of the human body dimensions currently available are limited to the physical body dimensions, such as the length or girth of a particular body part. Those dimensions are useful for appearance design, such as shape and form, but are not sufficient for software design, such as information architecture and style. For example, users with limited vision would have difficulty with reading small letters displayed on a mobile device. To overcome those limitations, human body dimensions should be extended to include other human functions, such as perceptional and cognitive ability.

There are two types of anthropometry: static and dynamic [2]. The former is the measurement taken in a rigid static posture, while the latter is the measurement taken into consideration of different movement. Traditional static anthropometric data have been obtained by measuring the distance between body landmarks in standardized postures [3]. However, human postures are continuously changed by various daily activities. When walking or running, all parts of the body are engaged to produce movement and the relative positions of landmarks are thus altered. From a design point of view, different types of interactions between the user and the product/service would alter the human body dimension and eventually lead to a decrease of the performance of the product/service. Even though the product/service was designed based on the anthropometric data, the performance and productivity would be valid only for the posture used for measurement.

This study aims to identify new types of human property measurements and suggest several perspectives to measure anthropometric data for user-centered design. We use the term "human property measurements" to represent both physical body dimensions and other characteristics, such as perceptional and cognitive ability. To find new perspectives on anthropometric data, we created user scenarios that explain various contexts of use.

\section{Method}

User scenarios defined in this study show diverse activities of various groups in a variety of situations. After defining three groups of context variables, brainstorming was used to create scenarios to combine three context variables. The human property measurements from each scenario were analyzed without any restriction. Finally, human property measurements were grouped into several categories. 


\section{Context variables}

Context variables were redefined based on those defined by [4], [5], and [6], which pertain to simulating various situations. The role of context variables is to suggest a scheme to specify the user scenarios. We excluded context variables related to specific products or services to prevent biased thinking. Context variables consist of the following three categories: user profile, user state, and environment (Table 1). In the user profile, there are three types of context variables: age, type of disability, and gender. Each context variable has several items; for example, age includes infant, child, adolescent, young adult, middle-aged adult, and elderly. User state represents context variables such as user task, body movement, physical/physiological state, and emotional/psychological state. Environment has three context variables: physical ambient conditions, location, and time.

Table 1. Context variables for scenario generation

\begin{tabular}{ll}
\hline Categories & Context variables \\
\hline \hline User profile & - Age (infant, child, adolescent, \\
& young adult, middle-aged adult, \\
& elderly) \\
& Type of disability (nondisabled, \\
& hearing disability, visual \\
& disability, physical disability, \\
& intellectual and developmental \\
& disabilities) \\
& Gender (male, female) \\
& - User task (housework, business, \\
& entertainment, eating, exercise, \\
& moving, singing) \\
& Body movement (posture, \\
& motion of the head, motion of \\
& the upper body, motion of the \\
& lower body) \\
& Physical/physiological state \\
& (health, disease, injury, fatigue, \\
& temperature, heart rate) \\
& Emotional/psychological state \\
& (happiness, sadness, neutrality, \\
& fear, anxiety, stress, sleepiness) \\
\hline & Physical ambient conditions \\
& (sound/noise, \\
& illumination, devices, objects) \\
& Location (home, shopping \\
& facilities, workplaces, road, \\
& restaurants, public facilities) \\
& Time (morning, noon, night) \\
\hline Environment &
\end{tabular}

\section{User scenarios and relevant human property dimension}

A total of 60 scenarios were created by combining three items, each of which was from the context variables. For example, the combination of "elderly" from the age variable, "entertainment" from the user task variable, and "devices" from the physical ambient environment variable leads to the following scenario: "it is difficult to read small letters on the visual display on TV, mobile devices, and computers." From this scenario, eyesight can be the relevant human property measurement. Another combination, this time including "visual disability" from type of disability, "moving" from user task, and "road" from location, leads to the following scenario: "people with visual disability exhibit a different walking pattern because they use a white cane." Relevant human property measurements can be "walking pattern."

By analyzing 60 scenarios, human property measurements were identified and grouped into eight categories. The number of created scenarios was presented in brackets.

- Perceptual dimension (14)

- Dynamic body dimension (11)

- Product- or service-specialized dimension (9)

- Emotional/psychological dimension (8)

- The elderly's posture-related dimension (7)

- Muscle strength of infants and the elderly (5)

- Disability-specialized dimension (3)

- Pregnancy-related dimension (3)

The perceptual dimension includes measurements related to the visual and hearing ability of all ages (Table 2). There are scenarios about adverse effect of environment and about decreased human functions.

The dynamic body dimension includes the range of motion of various body parts such as head, neck, wrist, and finger, and lower body (Table 3 ). This category also has dimensions such as muscle fatigue, load in ankle and knee, static and kinetic friction, and equilibrium sense.

The product- or service-specialized dimension represents measurements for specific products or services, including spoons or chopsticks, bus handles, button of the controller, and refrigerator door. The same measurements can be measured several times according to the user tasks involved when interacting with a product or service.

The emotional/psychological dimension is related to the stress, alertness, drowsiness, and ability to concentrate.

The elderly's posture-related dimension includes a variety of different measurements, including static body dimension in hunched posture and muscle strength of the hand when pushing or pulling the door.

The dimensions for muscle strength of infants and the elderly include muscle strength of the head, hands, chin, and lower body. Most scenarios show difficulties caused by weak muscle strength.

The disability-specialized dimension includes distinctive measurements arising from disabilities. For example, there can be measurements about the articulatory ability of people with hearing impairments.

Lastly, the pregnancy-related dimension represents the static body dimensions, such as circumference and weight of the belly, as well as the range of motion of the whole body. 
Table 2. Scenarios and dimensions related to perception

\begin{tabular}{|c|c|c|}
\hline \# & Scenarios & Related dimensions \\
\hline 1 & Watching TV too close is not good for the vision/hearing of infants. & $\begin{array}{l}\text { - Visual and hearing ability of an } \\
\text { infant }\end{array}$ \\
\hline 2 & $\begin{array}{l}\text { The ability to play with a mobile differs depending on the months of } \\
\text { age. }\end{array}$ & - Visual ability of an infant \\
\hline 3 & If a child uses a computer in the dark, their eyes become blurry. & - Visual ability of a child \\
\hline 4 & Adolescents read a book under the bright light for a long time. & - Visual ability of an adolescent \\
\hline 5 & Adolescents listen to music loudly all day. & - Hearing ability of an adolescent \\
\hline 6 & $\begin{array}{l}\text { Adolescents using earphones cannot hear other sounds, such as a } \\
\text { siren. }\end{array}$ & - Hearing ability of an adolescent \\
\hline 7 & Exposure to loud noise at a concert can cause a ringing in the ears. & - Hearing ability of an adolescent \\
\hline 8 & Outside noise makes it impossible to hear the listening test. & - Hearing ability of an adolescent \\
\hline 9 & Young adults working in a noisy place become temporarily deafened. & - Hearing ability of a young adult \\
\hline 10 & $\begin{array}{l}\text { When the sunlight is strong, drivers can hardly see the load in front } \\
\text { of them. }\end{array}$ & $\begin{array}{l}\text { - Visual ability of a middle-aged } \\
\text { adult }\end{array}$ \\
\hline 11 & Workers lose their footing on the steps when in a hurry. & $\begin{array}{l}\text { - Visual ability of a middle-aged } \\
\text { adult }\end{array}$ \\
\hline 12 & $\begin{array}{l}\text { Vision varies in different light-emitting displays, such as TVs, } \\
\text { computers, and mobile devices. }\end{array}$ & $\begin{array}{l}\text { - Visual ability of a middle-aged } \\
\text { adult }\end{array}$ \\
\hline 13 & $\begin{array}{l}\text { It is difficult to read small letters on the visual display of a } \\
\mathrm{TV} \text {, computer, and mobile device. }\end{array}$ & - Visual ability of an elderly adult \\
\hline 14 & $\begin{array}{l}\text { The elderly have difficulty with hearing the other people's voice duri } \\
\text { ng a phone call. }\end{array}$ & - Hearing ability of an elderly adult \\
\hline
\end{tabular}

Table 3. Scenarios and dimensions related to human body movements

\begin{tabular}{|c|c|c|}
\hline \# & Scenarios & Related dimensions \\
\hline 1 & $\begin{array}{l}\text { Drivers experience a physical overload on the neck when looking } \\
\text { around continuously. }\end{array}$ & $\begin{array}{l}\text { - Range of motion of the head } \\
\text { - Viewing distance }\end{array}$ \\
\hline 2 & $\begin{array}{l}\text { It is hard to put luggage in the overhead compartment in a subway or } \\
\text { a plane. }\end{array}$ & $\begin{array}{l}\text { - Muscle strength } \\
\text { - Range of motion of the upper body }\end{array}$ \\
\hline 3 & The way of walking affects the growth of the child. & $\begin{array}{l}\text { - Walking-related dimensions (stride, } \\
\text { angle, pressure, etc.) }\end{array}$ \\
\hline 4 & $\begin{array}{l}\text { An infant has difficulty with outstretching their arms when wearing a } \\
\text { cloth. }\end{array}$ & - Range of motion of the upper body \\
\hline 5 & $\begin{array}{l}\text { The space design of kindergarten may be too high or too steep for } \\
\text { infants. }\end{array}$ & - Range of motion of the infants \\
\hline 6 & Using a mouse and keyboard for a long time strains the upper body. & $\begin{array}{l}\text { - Muscle fatigue } \\
\text { - Range of motion of the neck, wrist, } \\
\text { and finger. }\end{array}$ \\
\hline 7 & The elderly cannot easily cross the threshold. & - Range of motion of the lower body \\
\hline 8 & A downhill course of hiking can bring about joint pain. & - Load in ankle and knee \\
\hline 9 & $\begin{array}{l}\text { Young adults are vulnerable to slipping in swimming pools and } \\
\text { baths. }\end{array}$ & - Static and kinetic friction \\
\hline 10 & Pregnant women easily become tired during their daily lives. & - Load in ankle and knee \\
\hline 11 & $\begin{array}{l}\text { The elderly are at greater risk of slipping on a wet surface, such as } \\
\text { an icy road. }\end{array}$ & $\begin{array}{l}\text { - Sense of equilibrium } \\
\text { - Static and kinetic friction }\end{array}$ \\
\hline
\end{tabular}

\section{Discussion}

Although many countries have measured perceptual dimensions, the purpose of such measurements was to provide suggest the statistics related to diseases, including glaucoma, cataracts, and inflammation. We can infer the direction for the future anthropometry database of the Research Institute of Human Engineering for Quality Life (HQL) in Japan [7]. HQL provides measurements for visual, hearing, haptic, and olfactory ability under various circumstances, such as 
visual acuity in different illumination, visual acuity when watching light-emitting displays, ability to distinguish colors, and dark adaptation. Moreover, they provide guidelines for ergonomic design; for example, appropriate letter size and volumes.

With the advance in 3D human body scanning technologies, all landmarks can be tracked during body movement [3]. By simulating various activities, the change in the human body measurements can easily be detected. When interacting with products or services, humans make different types of body motion; for example, stretching the arm to remove the goods from the shelves or steering the steering wheel in a car. By using 3D scanning technologies, dynamic body dimensions considering different user tasks would be easily measured.

Anthropometric data should cover a range of groups, such as the disabled, infants, pregnant women, and the elderly. As the population continues to age, it is necessary to take into account the needs of the elderly when designing products and services in the silver industry. Anthropometric data for the elderly should be measured with consideration for the changes in body posture caused by chest kyphosis [8]. Human property dimensions for each group can be identified more in detail through ethnographic research.

Recently, user emotions elicited by product appearance are critical elements for affective design [9]. For affective design, the emotional/psychological dimension identified in this study, such as stress, anxiety, and sleepiness, should be measured and provided.

\section{Conclusion}

This study suggested new types of human property dimensions by creating various user scenarios. For efficient and comprehensive scenario creation, we defined context variables. A total of 60 scenarios and related body dimensions were identified. Those dimensions were classified into the following eight categories: the perceptual dimension, the dynamic body dimension, the product- or service-specialized dimension, the emotional/psychological dimension, the elderly's posture-related dimension, the muscle strength of infants and the elderly dimension, the disabledspecialized dimension, and the pregnancy-related dimension. This study demonstrated that the various human property measurements could be efficiently derived from the user scenarios. The list of human property measurements developed in this study can be measured and provided for designing user-centered products and services.

\section{Acknowledge}

This research was supported by Basic Science Research Program through the National Research Foundation of Korea (NRF) funded by the Ministry of Education, Science and Technology (NRF2013R1A1A2013231).

\section{References}

[1] Sadeghi, F., Mazloumi, A., and Kazemi, Z.: An anthropometric data bank for the Iranian working population with ethnic diversity, Applied Ergonomics, 48, 95-103, 2015.

[2] Wang, E.M., Wnag, M., Yeh, W., Shih, Y., and Lin, Y.: Development of anthropometric work environment for Taiwanese workers, International Journal of Industrial Ergonomics, 23, 3-8, 1999.

[3] Sims, R.E., Marshall, R., Gyi, D.E., Summerskill, S.J., and Case, K. : Collection of anthropometry from older and physically impaired persons:

Traditional methods versus $\mathrm{TC}^{2} 3$-D body scanner, International Journal of Industrial Ergonomics, 42, 65$72: 2012$.

[4] Han, S. H., Park, J., Park, Y., and Cho, Y.: A systematic framework for generation of new business items using human factors knowledge: A scenario-based approach for mobile business, Asian Journal of Ergonomics, 6(1), 27-38, 2005.

[5] Kwahk, J. and Han, S. H.: A methodology for evaluating the usability of audiovisual consumer electronic products", Applied Ergonomics, 33(5), 419431, 2002.

[6] Park, J., Han, S. H., Yoo, Y., Park, Y., Cho, Y., Koo, J., and Cho, C.: Incorporating human factors knowledge into generating new business items: A scenario-based approach for mobile business, proceed. Of the 7th PanPacific Conference on Occupational Ergonomics, 119124, Cairns, Australia, 2004.

[7] HQL.: database of human body dimensions, available from http://www.hql.jp/, 2015.

[8] Jarosz, E.: Anthropometry of elderly women in Poland: dimensions for design, International Journal of Industrial Ergonomics 25, 203-213, 1999.

[9] Lu, W., and Petiot, J.: Affective design of products using an audio-based protocol: Application to eyeglass frame, International Journal of Industrial Ergonomics 44, 383-394, 2014. 